\title{
Braking Torque Closed-Loop Control of Switched Reluctance Machines for Electric Vehicles
}

\author{
He Cheng ${ }^{*}$, Hao Chen ${ }^{\dagger}$, Zhou Yang ${ }^{*}$, and Weilong Huang ${ }^{*}$ \\ ${ }^{\dagger *}$ School of Information and Electrical Engineering, China University of Mining and Technology, Xuzhou, China
}

\begin{abstract}
In order to promote the application of switched reluctance machines (SRM) in electric vehicles (EVs), the braking torque closed-loop control of a SRM is proposed. A hysteresis current regulator with the soft chopping mode is employed to reduce the switching frequency and switching loss. A torque estimator is designed to estimate the braking torque online and to achieve braking torque feedback. A feed-forward plus saturation compensation torque regulator is designed to decrease the dynamic response time and to improve the steady-state accuracy of the braking torque. The turn-on and turn-off angles are optimized by a genetic algorithm (GA) to reduce the braking torque ripple and to improve the braking energy feedback efficiency. Finally, a simulation model and an experimental platform are built. The simulation and experimental results demonstrate the correctness of the proposed control strategy.
\end{abstract}

Keywords: Braking energy feedback, Braking torque control, Electric Vehicles (EVs), Switched Reluctance Machine (SRM)

\section{INTRODUCTION}

Switched reluctance machines (SRM) have the advantages of robust construction, low production cost, a large starting torque, a wide speed range and good fault-tolerance capability. As a result, they are widely used in industrial and domestic applications [1]-[4]. SRMs have been successfully applied to integrated starter/generator (ISG) systems [5]-[7], flywheel energy storage systems [8], wind power generation systems [9], [10] and aircraft power supply systems [11]. Based on various applications, different control strategies for SRM drive systems have been employed [12]-[15]. The speed closed-loop control was designed by the auto disturbance rejection control in changeful reference speed, large load disturbance and variable system parameters applications, and it has good robustness to external load disturbances and internal model changes [12]. The multi-objective optimization was developed by tuning the turn-on and turn-off angles automatically to obtain a high motoring torque,

Manuscript received Oct. 17, 2014; accepted Jan. 10, 2015

Recommended for publication by Associate Editor Dong-Hee Lee.

${ }^{\dagger}$ Corresponding Author: hchen@cumt.edu.cn

Tel: +86-13013993107, Fax: +81-0516-83884587, China Univ. of Mining \& Tech.

* School of Information and Electrical Engineering, China University of Mining and Technology, China

${ }^{* *}$ School of Electrical Engineering, Hangook University, Seoul, Korea low copper loss, and a low torque ripple for EV applications [13]. As with the conventional motors, a SRM can be worked as a generator by regulating the turn-on and turn-off angles. This is known as a switched reluctance generator (SRG). In generating applications, the dc-link voltage closed-loop control is the most common control strategy. The power circuit components and the dynamic commutation shift controller are designed to minimize the dc-link voltage ripples caused by the commutation and pulse width modulation switching [14]. When the SRG is operated at high speeds with single pulse control, the turn-off angles are regulated online to optimize the efficiency, and turn-on angle is regulated by the power controller to guarantee the closed-loop control of the output power [15]. When the SRG workes at a low speed with current regulation, a two-loop control algorithm is developed to control the turn-on angle, turn-off angle and the peak value of the phase current to minimize the dc-link current ripple and to generate the required current [16]. As can be seen from above control methods, secondary objectives like minimizing the torque ripple, maximizing the efficiency and minimizing the dc-link current ripple should be taken into account when the one of main objectives comprising the rotating speed, dc-link voltage, dc-link current and generating power of the closed-loop controls is achieved [17].

The motoring operation of the SRMs for EVs has been 


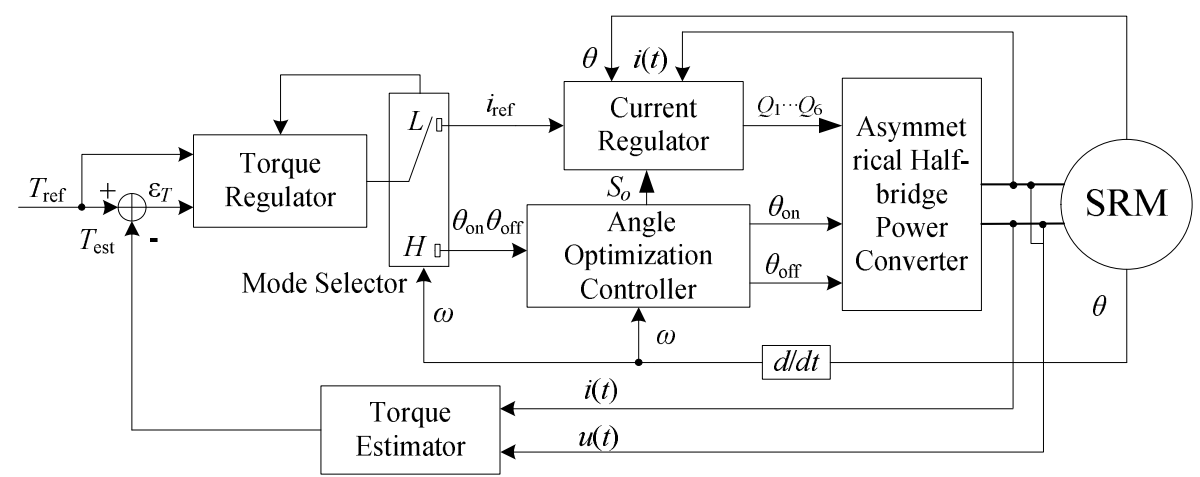

Fig. 1. Braking torque closed-loop control structure diagram of SRM.

discussed in [12], [13], [18], [19], and the speed closed-loop control is usually adopted. However, when EVs run in the braking energy feedback state, the above control strategies are not appropriate. Therefore, in this paper, the braking torque closed-loop control of the SRMs for EVs is proposed. The main control objective is to track a given braking torque. Therefore, the torque estimator is designed to estimate the braking torque and to achieve braking torque feedback. A feed-forward plus saturation compensation torque regulator is designed to improve the dynamic performance and steady-state accuracy of the braking torque. The secondary objectives are a high efficiency and a small torque ripple. As a result, a hysteresis current regulator with the soft chopping mode is employed to reduce the switching frequency and switching loss. The turn-on and turn-off angles are optimized by a genetic algorithm (GA) to achieve a satisfying balance between the braking energy feedback efficiency and the braking torque ripple.

\section{MATHEMATICAL EQUATIONS OF THE SRM}

Without consideration of the mutual inductance between the phase windings, one phase voltage equation of the SRM can be expressed as:

$$
\begin{gathered}
u=R i+\frac{d \psi(i, \theta)}{d t}=R i+l(i, \theta) \frac{d i}{d t}+e(i, \theta) \\
l=\frac{\partial \psi(i, \theta)}{\partial i} \\
e=\omega_{r} \frac{\partial \psi(i, \theta)}{\partial \theta}=\omega_{r} \frac{\partial L(i, \theta)}{\partial \theta} i
\end{gathered}
$$

where $u, i, R, \psi, l(i, \theta), e(i, \theta)$ and $\omega_{r}$ represent the phase voltage, phase current, winding resistance, flux linkage, increment inductance, back EMF and rotor angle velocity, respectively.

The torque production of the SRM is based on the principle of minimum reluctance, i.e., the excited stator poles attract the nearest rotor poles to minimize the reluctance of the closed magnetic path. According to the principle of electromechanical energy conversion, the torque of the SRM can be written as:

$$
\begin{aligned}
& T_{e}=\left.\frac{\partial W_{m}{ }^{\prime}(i, \theta)}{\partial \theta}\right|_{i=c o n s t} \\
& W_{m}{ }^{\prime}=\int_{0}^{i} \psi d i
\end{aligned}
$$

where $W_{m}{ }^{\prime}$ is the co-energy.

Assuming that the saturation characteristic of the SRM is ignored, substituting Eq. (5) in Eq. (4) yields:

$$
T_{e}=\frac{\partial \int_{0}^{i} L(\theta) i d i}{\partial \theta}=\frac{1}{2} \frac{d L(\theta)}{d \theta} i^{2}=\frac{1}{2} k_{L} i^{2}
$$

where $k_{L}=d L(\theta) / d \theta$ stands for the unsaturated inductance slope.

\section{BRAKING TORQUE CLOSED-LOOP CONTROL}

In order to track a given braking torque online and convert the braking energy into electric energy stored in a battery when a SRM is applied to electric vehicle drive motors, the braking torque closed-loop control strategy is proposed as shown in Fig. 1.

The control system is composed of a current regulator, a mode selector, a torque estimator, a torque regulator and an angles optimization controller. A torque external loop and a current internal loop are adopted in the SRM drive system. The current regulator realizes the internal current tracking. The angle optimization controller implements the angle optimization at low speeds, and the single pulse control does this at high speeds. The mode selector chooses the corresponding control modes according to the speed. The torque estimator estimates the average torque online and gives feedback to the torque regulator to achieve the braking torque closed-loop control.

\section{A. Current Regulator}

Due to the nonlinearity of the inductance versus the rotor position and phase current, it is difficult for a fixed gain PI controller to track the reference phase current well in SRM drive systems. Lots of papers have researched gain-scheduling PI current regulators, but the complexity and computational burden of the controller are increased [20], 


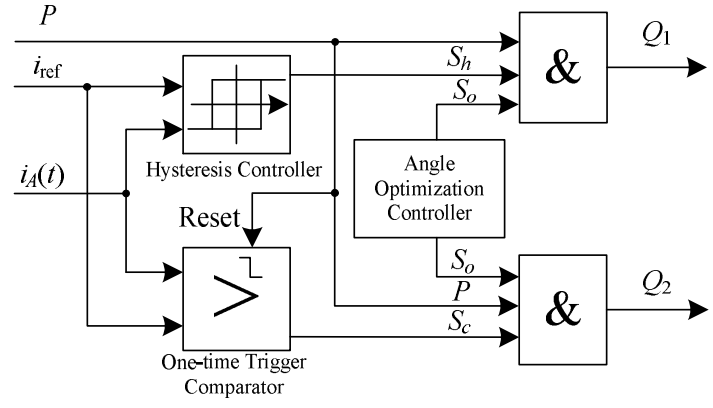

(a)

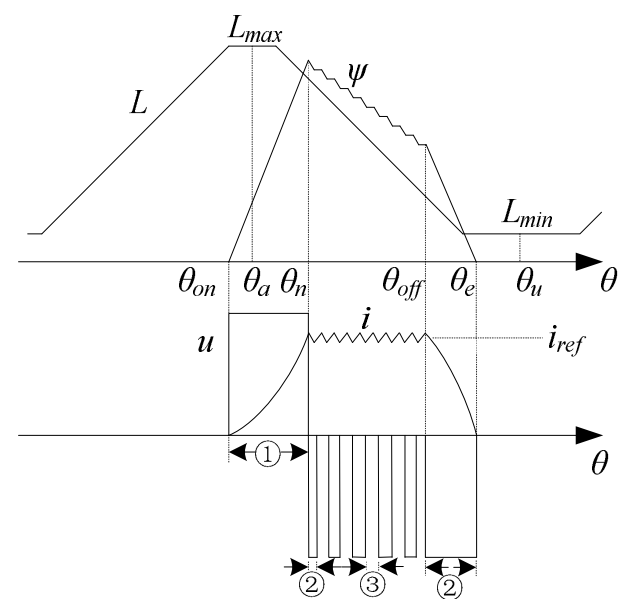

(b)

Fig. 2. Hysteresis current regulator. (a) Structure diagram of A phase current regulator. (b) Typical waveforms.

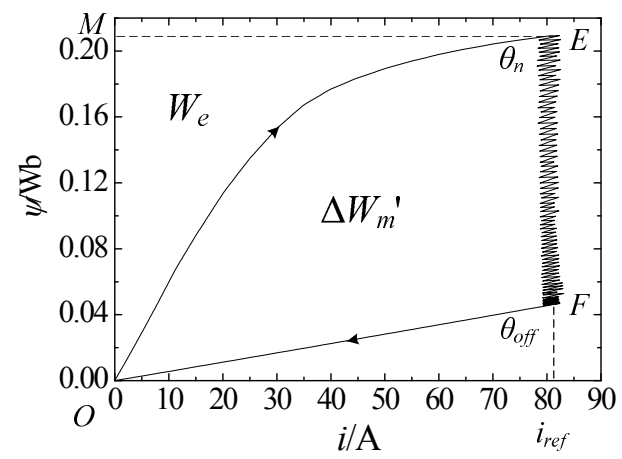

Fig. 3. Flux/current waveform.

[21]. A robust hysteresis current regulator with a soft chopping mode is devised to reduce the switching frequency and switching loss. The structure diagram of the $A$ phase current regulator is shown in Fig. 2(a). The $B$ and $C$ phase current regulators are similar.

In Fig. 2(a), $P$ is the rotor position signal of the $A$ phase, whose rising and falling edges represent the minimum and maximum inductance areas of the $A$ phase. The hysteresis controller compares the actual phase current $i_{\mathrm{A}}$ with the reference phase $i_{\text {ref }}$ and outputs the switching signal $S_{\mathrm{h}}$. The angle optimization controller outputs the optimized conduction angle signal $S_{\mathrm{o}}$. Then the signals $P, S_{\mathrm{h}}$ and $S_{\mathrm{o}}$ are inputted into the AND gate to generate the chopping signal $Q_{1}$ for the upper switch. A one-time trigger comparator with a falling edge reset is used for the control of the lower switch. When $i_{\mathrm{A}}$ is bigger than $i_{\text {ref }}$ for the first time, the output of the comparator changes into a low level from a high level and remains a low level regardless of the input signals until the falling edge of the rotor position signal $P$ resets the comparator. The output of the comparator is $S_{\mathrm{c}}$. Then the signals $P, S_{\mathrm{c}}$ and $S_{\mathrm{o}}$ are inputted into the AND gate to generate the chopping signal $Q_{2}$ for the lower switch. The typical phase voltage, phase current and flux linkage waveforms are shown in Fig. 2(b). (1) is the initial excitation; (2) is the power generation; (3) is the zero-voltage freewheeling.

\section{B. Torque Estimator}

There is no accurate mathematical model for the SRM, and it is difficult to build an analytic expression of torque. Therefore, the energy method is used to estimate the average torque of the SRM. Fig. 3 shows the flux/current waveform of one excitation cycle. The area $W_{e}$ encompassed by $O E M$ denotes the excitation energy of one excitation period, and the area $\Delta W_{m}{ }^{\prime}$ encompassed by $O E F$ represents the co-energy variation of one excitation cycle. $\Delta W_{m}{ }^{\prime} /\left(\Delta W_{m}{ }^{\prime}+W_{e}\right)$ stands for the energy conversion ratio.

As can be observed from Fig. 3, $\Delta W_{m}^{\prime}$ represents the co-energy variation of one excitation cycle. By combining Eqns. (4) and (5), the average torque of the SRM can be expressed as:

$$
\begin{aligned}
& T_{\text {ave }}=\frac{\Delta W_{m}{ }^{\prime}}{\Delta \theta}=\frac{m N_{r}}{2 \pi} \oint \psi d i \\
& \psi=\int(u-R i) d t+\psi_{0}
\end{aligned}
$$

where $m, N_{r}$ and $\psi_{0}$ represent the phase number, rotor pole number and initial flux linkage, respectively.

At the end of each electrical cycle, the flux linkage and phase current turn to zero. As a result, the $\psi_{0}$ in Eq. (8) is zero. The average torque estimator is designed based on Eqns. (7) and (8), which is shown in Fig. 4(a).

In Fig. 4(a), the average torque estimator is made up of a flux linkage integrator, a co-energy integrator, a zero-cross detector, a sampling holder and a multiplier. The flux linkage integrator is used to output the flux linkage $\psi$ via the time integral of $(u-i \cdot R)$. The co-energy integrator outputs the co-energy $W_{m}{ }^{\prime}$ by integrating $\psi$ with respect to the phase current $i$. The two integrators are resettable, which can guarantee that the outputs are zero at the end of each cycle, and eliminate the accumulation error. The zero-cross detector outputs the reset signals to the two integrators when the phase current turns to zero. It also outputs the trigger signal to the sampling holder. This moment sampling holder samples the co-energy variation $\Delta W_{m}{ }^{\prime}$ over the current electrical cycle and holds it until the next trigger signal. Finally, the average 


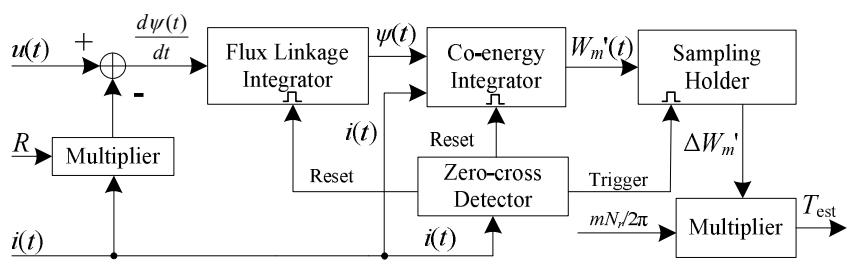

(a)

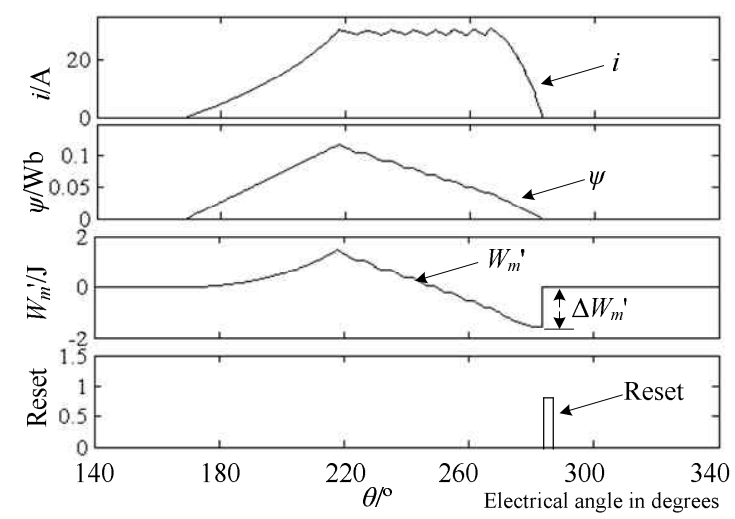

(b)

Fig. 4. Average torque estimator. (a) Structure diagram of average torque estimator. (b) Typical waveforms.

torque $T_{\text {est }}$ can be obtained by multiplying $\Delta W_{m}{ }^{\prime}$ with $m N_{r} / 2 \pi$. Fig. 4(b) shows the typical waveforms. It includes the phase current, flux linkage, co-energy and reset signal from the top to the bottom.

\section{Torque Regulator}

When the SRM is operated in the linear region, the inductance is a trapezoidal function versus the rotor position as shown in Fig. 2(b). As can be derived from Eq. (6), the torque is proportional to the square of the phase current. However, in order to enhance the energy conversion ratio, the SRM should be operated in the saturation state, and the inductance is a nonlinear function versus the rotor position and the phase current. The composite torque regulator in consideration of the saturation characteristic of the SRM is designed as shown in Fig. 5.

The proposed torque regulator is composed of two parts: the torque feed-forward segment and the saturation compensation segment. When the SRM is operated in the linear region, the feed-forward segment outputs the feed-forward current $i_{f}$ according to Eq. (6). By considering the saturation characteristic of the SRM in the practical work state, the saturation compensation segment is added. The error torque $\varepsilon_{T}$ between the reference torque $T_{\text {ref }}$ and the estimated torque $T_{\text {est }}$ is inputted into the PI regulator, and then the PI regulator outputs the saturation compensation current $i_{c}$ to eliminate the static error. The sum of $i_{f}$ and $i_{c}$ constitutes the reference current $i_{\text {ref }}$ of the internal current loop, which is inputted into the current regulator. The torque feed-forward segment could enhance the dynamic performance and the

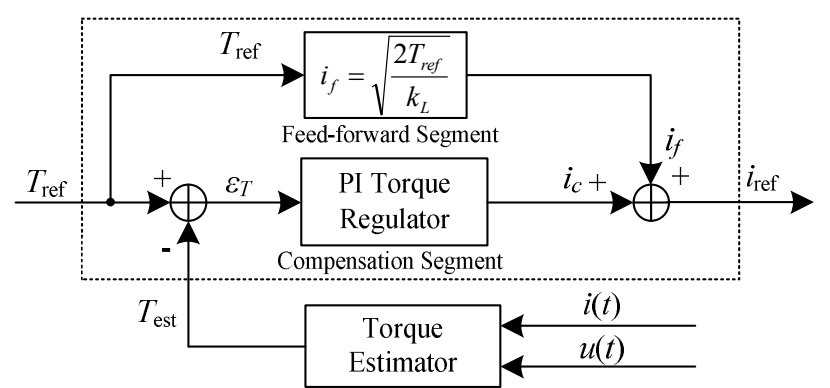

Fig. 5. Composite torque regulator.

saturation compensation segment could improve the steady-state accuracy of the braking torque.

\section{Switching angles optimization controller}

In the SRM torque control system, the optimal turn-on and turn-off angles could reduce the torque ripple and increase the braking energy feedback efficiency. Due to the nonlinearity of the SRM drive system, it is hard to optimize the switching angles by the traditional analytical methods. A genetic algorithm (GA) is based on the natural selection and genetic mechanism of the survival of the fittest. It performs selection, crossover and mutation based on a fitness function. The individuals with a large fitness function value are reserved and make up the new population. The fitness of the population keeps the sustainable improvements until the predefined evolution generations or until the threshold value is achieved. The search strategy and optimization calculation of a GA are not dependent on the gradient information, so it is suitable for dealing with complex nonlinear problems [22].

To evaluate the braking torque ripple and braking efficiency of the SRM drive system, two indicators are adopted: the braking torque smooth factor $\tau$ and the braking efficiency $\eta$

$$
\tau=\frac{T_{\text {ave }}}{T_{\max }-T_{\min }}
$$

where $T_{\text {ave }}, T_{\max }$ and $T_{\min }$ denote the average braking torque, maximum instantaneous braking torque and minimum instantaneous braking torque, respectively.

$$
\eta=\frac{P_{G e n}}{P_{\text {Mech }}}=\frac{I_{C h} U_{B a t}}{T_{\text {ave }} \omega}
$$

where $P_{G e n}, P_{M e c h}, I_{C h}$ and $U_{B a t}$ represent the generating power, input mechanical power, charging current and voltage of the battery, respectively.

In order to obtain the optimal $\theta_{\text {on }}$ and $\theta_{\text {off }}$ in consideration of a trade-off between the torque ripple and the efficiency, the following fitness function is designed:

$$
\begin{aligned}
& f(\tau, \eta)=w_{\tau} \frac{\tau}{\tau_{\max }}+w_{\eta} \frac{\eta}{\eta_{\max }} \\
& w_{\tau} \geq 0, \quad w_{\eta} \geq 0, \quad w_{\tau}+w_{\eta}=1
\end{aligned}
$$

where $w_{\tau}, w_{\eta}, \tau_{\max }$ and $\eta_{\max }$ stand for the weight coefficient of 


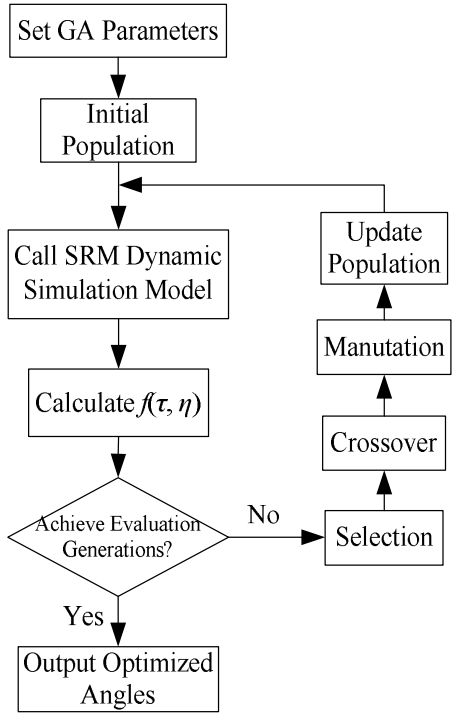

Fig. 6. GA optimization flow chart of $\theta_{\text {on }}$ and $\theta_{\text {off. }}$

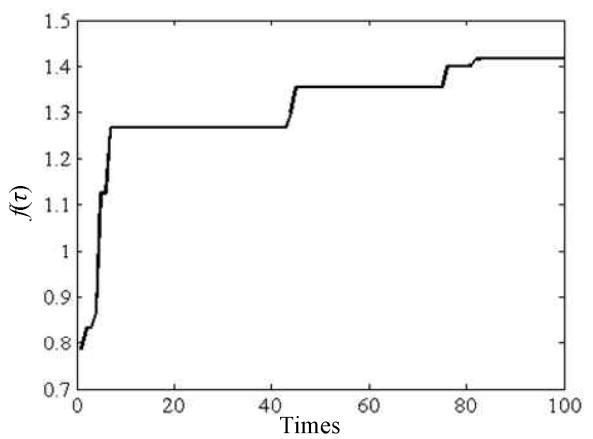

(a)

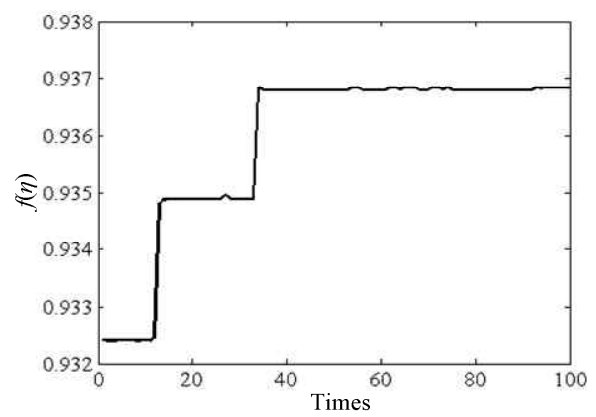

(b)

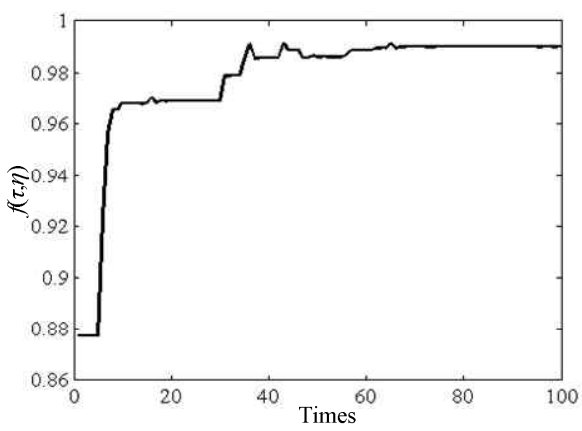

(c)

Fig. 7. GA optimization process. (a) $f(\tau)$ optimization. (b) $f(\eta)$ optimization. (c) $f(\tau, \eta)$ optimization. $\tau$, the weight coefficient of $\eta$, the optimal $\tau$ and the optimal $\eta$, respectively.

In Eq.(11), $w_{\tau}$ and $w_{\eta}$ can be determined according to the requirements of applications. In addition, $\tau_{\max }$ can be obtained by a GA based on the fitness function Eq.(12), which means that only the torque ripple is optimized. $\eta_{\max }$ can be obtained by a GA based on the fitness function Eq.(13), which means that only the efficiency is optimized

$$
\begin{aligned}
& f(\tau)=\tau \\
& f(\eta)=\eta
\end{aligned}
$$

The GA optimization flow chart of $\theta_{\text {on }}$ and $\theta_{\text {off }}$ is shown in Fig. 6. Firstly, initialize the GA parameters. The ranges of $\theta_{\text {on }}$ and $\theta_{\text {off }}$ are restricted to $\left[18^{\circ}, 28^{\circ}\right]$ and $\left[30^{\circ}, 40^{\circ}\right]\left(0^{\circ}\right.$ or $45^{\circ}$ is unaligned position, $22.5^{\circ}$ is aligned position). Then, set the population size $M=20$, the evolution generation $G=100$, the crossover probability $P_{\mathrm{c}}=0.60$, and the adaptive mutation probability $P_{\mathrm{m}}=0.001-[1: 1: M]^{*} 0.001 / M$. Then initialize the population, call the SRM dynamic simulation model built in Matlab/Simulink and calculate the fitness function. Then judge whether to reach to the predefined evolution iterations. If not, perform the selection, crossover and mutation to produce offspring and update the population; if yes, output the optimal $\theta_{\text {on }}$ and $\theta_{\text {off. }}$.

Fig. 7 shows the optimization process of the switching angles. The designed fitness function values increase along with the evolution iterations increment. Fig. 7(a) shows the optimization process with the fitness function (12), i.e., only the torque ripple is optimized and $\tau_{\max }=1.418$. Fig. 7(b) shows the optimization process with the fitness function (13), i.e., only the braking energy feedback efficiency is optimized and $\eta_{\max }=93.68 \%$. To achieve a satisfying balance between the braking efficiency and the braking torque ripple, fitness function (11) is adopted with $w_{\tau}=0.3$ and $w_{\eta}=0.7$. The GA optimization process is shown in Fig. 7(c), and the optimized indicator values are $\tau=1.397$ and $\eta=92.58 \%$.

\section{SIMULATION AND EXPERIMENTAL RESULTS}

To test the braking torque closed-loop system and the proposed control strategies, a simulation model is built in Matlab/Simulink. The flux linkage and torque characteristics of the SRM in simulation model are obtained by finite element analysis (FEA). Then the SRM test system is built as shown in Fig. 8. The experimental platform is composed of a three-phase $12 / 8$ pole SRM, a torque sensor and a dynamometer as shown in Fig. 8(a). The power converter, supply power, controller and driver are shown in Fig. 8(b). The SRM specifications are shown in Table I.

Fig. 9 shows the simulated phase current and phase voltage waveforms at $400 \mathrm{r} / \mathrm{min}$ and $3000 \mathrm{r} / \mathrm{min}$. The current chopping control is adopted at a low speed as shown in Fig.9 (a). Zero voltage and negative voltage are supplied in the demagnetization stage. Soft chopping could reduce the 


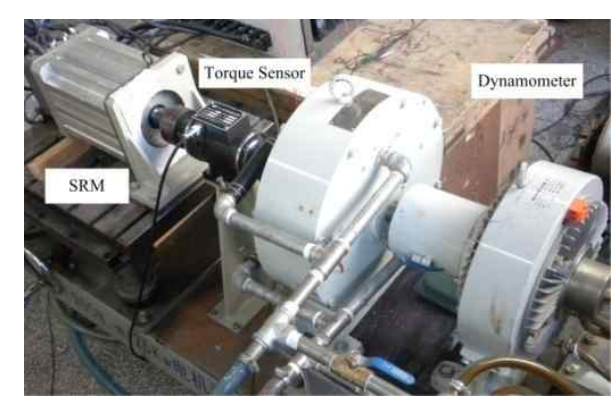

(a)

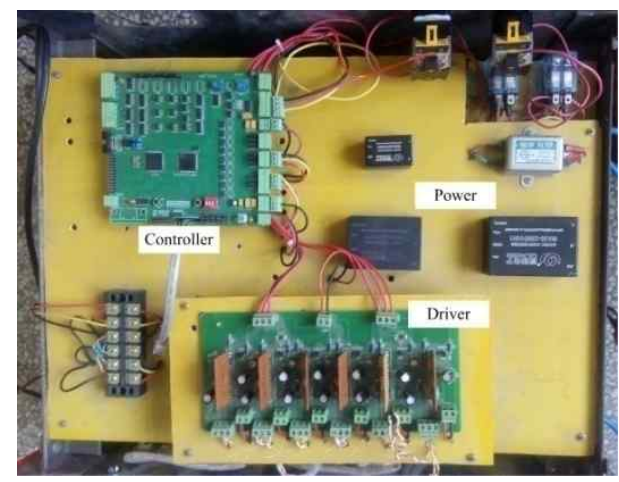

(b)

Fig. 8. SRM test system. (a)Experimental platform. (b) Control system.

TABLE I

SRM SPECIFICATIONS

\begin{tabular}{|c|c|}
\hline Phase number & 3 \\
\hline Stator/Rotor & $12 / 8$ \\
\hline Supply voltage & $96 \mathrm{~V}$ \\
\hline Rated torque & $25 \mathrm{Nm}$ \\
\hline Rated speed & $1300 \mathrm{r} / \mathrm{min}$ \\
\hline
\end{tabular}

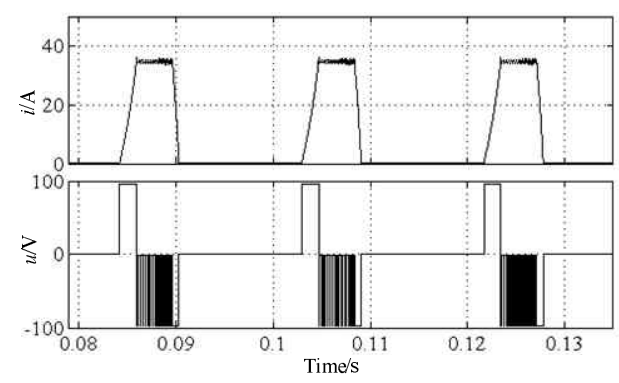

(a)

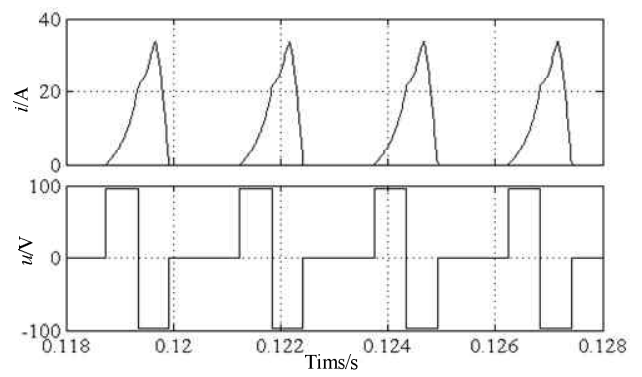

(b)

Fig. 9. Simulated current and voltage waveforms. (a) $400 \mathrm{r} / \mathrm{min}$. (b) $3000 \mathrm{r} / \mathrm{min}$.

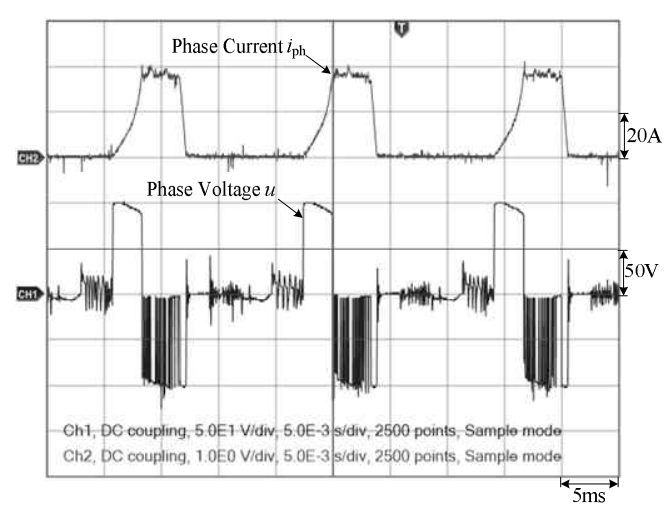

(a)

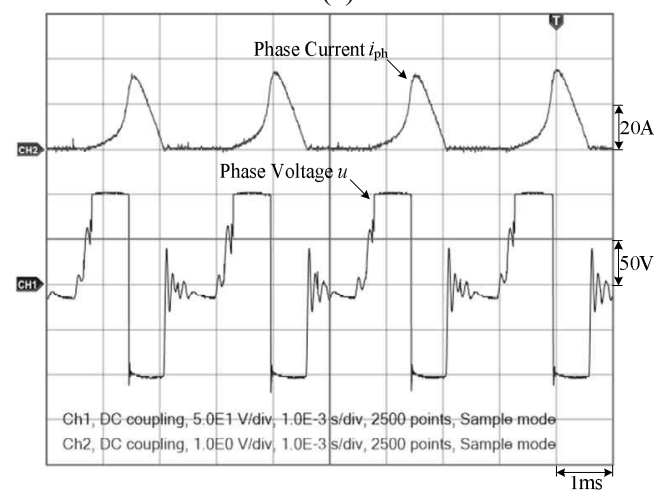

(b)

Fig. 10. Experimental phase current and phase voltage waveforms. (a) $400 \mathrm{r} / \mathrm{min}$. (b) $3000 \mathrm{r} / \mathrm{min}$.

switching frequency and switching loss. With the speed increment, the back EMF increases and the zero-voltage freewheeling stages disappear. Then the single pulse control is adopted at a high speed as shown in Fig. 9(b). Fig. 10 shows the experimental phase current and phase voltage waveforms obtained by hall current and voltage sensors in the experimental platform.

Fig. 11 shows the simulated torque estimate waveforms and includes the phase current, flux linkage, co-energy, estimated torque and actual torque from the top to the bottom. Fig. 12 shows the experimental torque estimate waveforms, and the estimated braking torque is displayed with a positive value. As can be seen from both the simulation and the experiment, the estimated torque tracks the actual torque well. Therefore, the torque estimator can quickly give the braking torque feedback to the torque regulator online. This can improve the dynamic performance of the drive system.

Fig. 13(a) shows the simulated composite torque regulator waveforms. The reference current $i_{\text {ref }}$ is the sum of the feed-forward current $i_{f}$ and the saturation compensation current $i_{c}$. When the reference torque $T_{\text {ref }}$ is $6 \mathrm{Nm}$, the value of $i_{f}$ output by the feed-forward segment is $24.5 \mathrm{~A}$. $i_{c}$ is output by the PI regulator to eliminate the static torque error. When $\mathrm{t}=0.15 \mathrm{~s}$, the value of $T_{\text {ref }}$ increases to $8 \mathrm{Nm}$, and the value of $i_{f}$ increases to $28.3 \mathrm{~A}$. The value of $i_{c}$ is enlarged by the PI regulator gradually. As can be seen, $i_{c}$ increases with the 


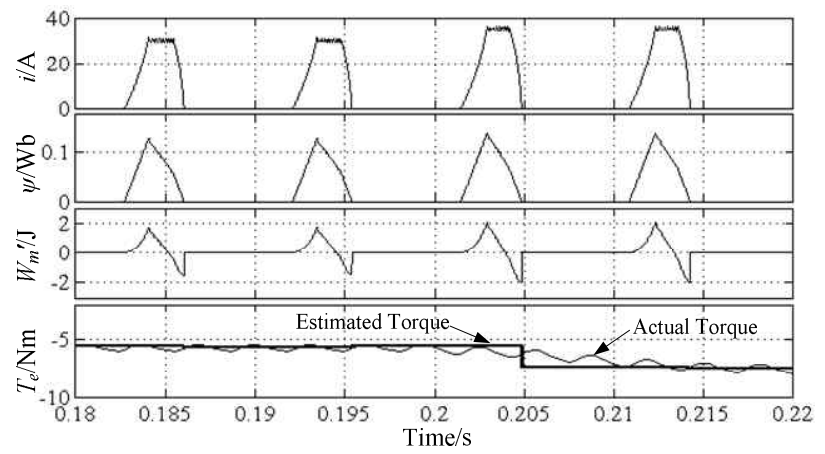

Fig. 11. Simulated torque estimate waveforms.

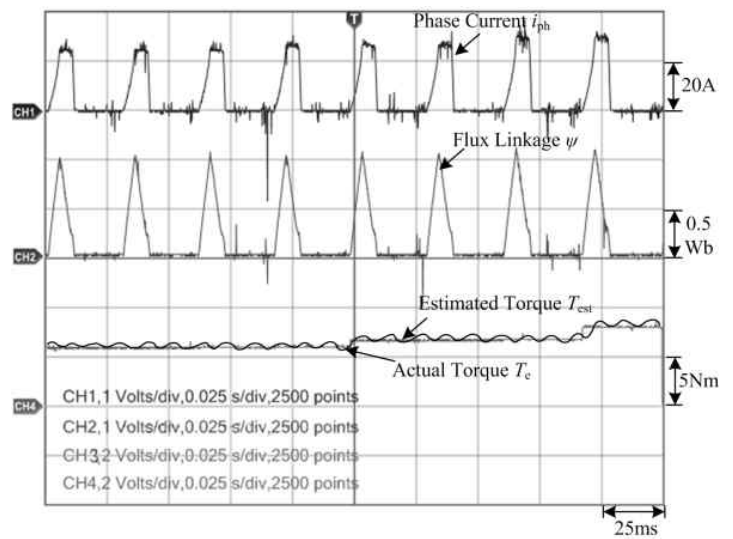

Fig. 12. Experimental torque estimate waveforms.
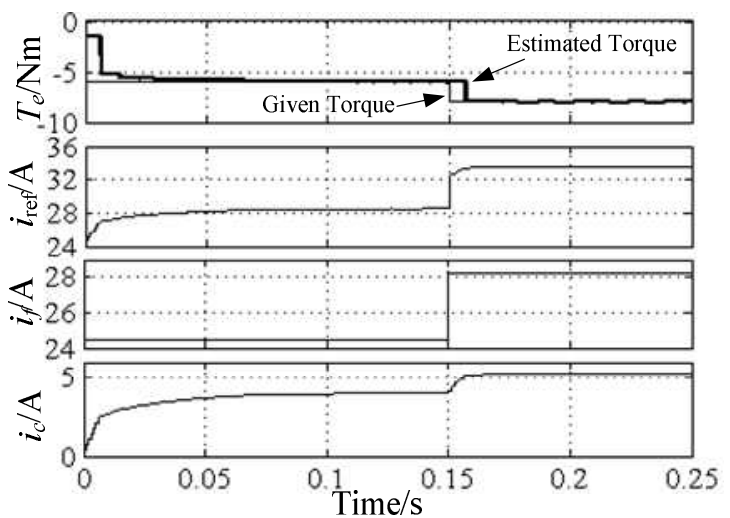

(a)
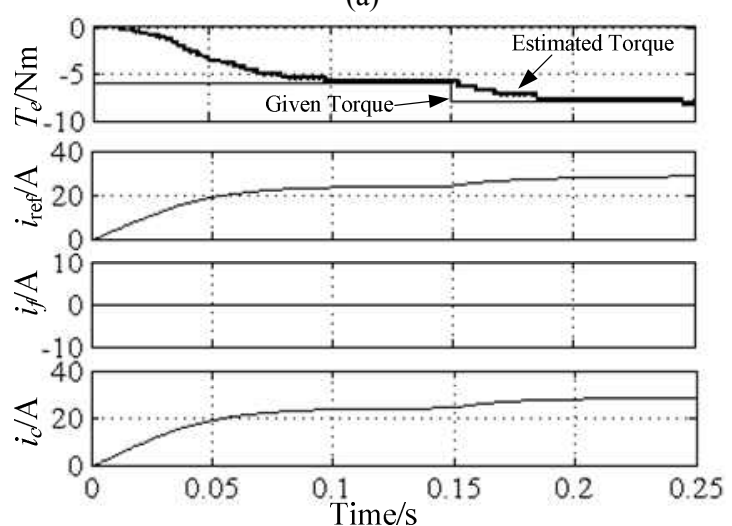

(b)

Fig. 13. Simulated torque regulator waveforms. (a) Composite torque regulator. (b) PI torque regulator.

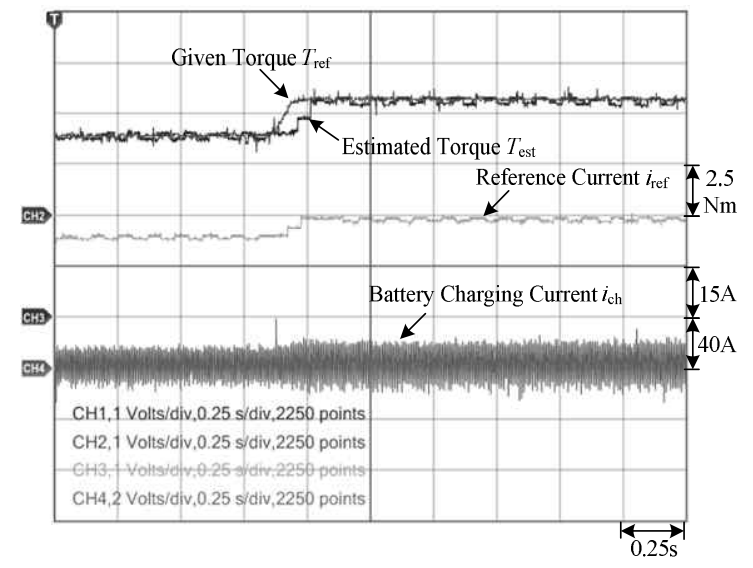

(a)

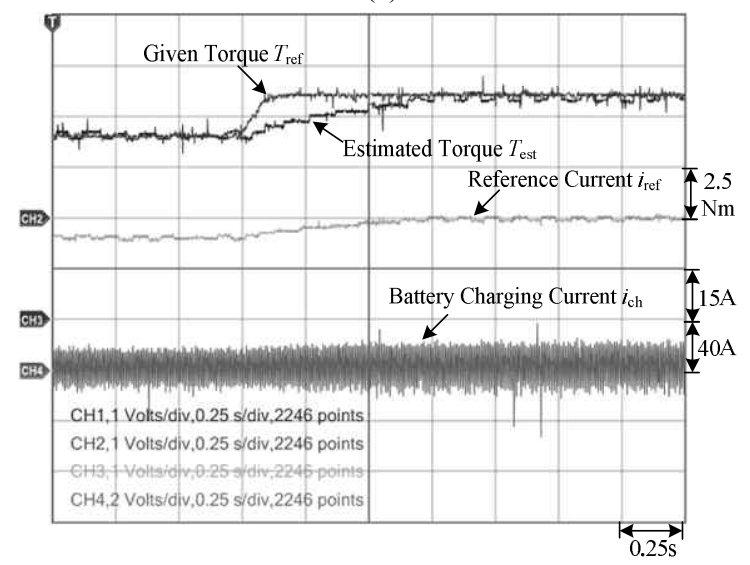

(b)

Fig. 14. Experimental torque regulator waveforms. (a) Composite torque regulator. (b) PI torque regulator.

increase of the saturation level of the SRM. Fig. 13(b) shows the traditional PI regulator waveforms. It can be seen that its dynamic response speed is slower than the proposed composite regulator. Fig. 14 shows the experimental torque regulator waveforms. The settling time of the proposed regulator is $0.12 \mathrm{~s}$, and the settling time of the traditional PI regulator is $0.65 \mathrm{~s}$, so the response speed is improved by more than five times. It also can be seen from $\mathrm{CH} 4$ that the battery charging current increases with the braking torque increment.

The simulated phase current and toque waveforms with optimal values of $\theta_{\text {on }}$ and $\theta_{\text {off }}$ are shown in Fig. 15. As shown in Fig. 15(a), the phase current RMS is large, i.e., the copper loss is large and the braking efficiency is low when only the braking torque ripple is optimized. As shown in Fig. 15(b), the braking torque ripple is large when only the system efficiency is optimized. As shown in Fig. 15(c), the braking torque ripple is small and the braking efficiency is high when the two indicators are optimized simultaneously. Fig. 16 shows the experimental waveforms, and $\mathrm{CH} 2$ is the battery charging current. It can be seen that the dc-link current ripple is small when the braking torque ripple is small. Therefore, the optimal switching angles can reduce both the braking torque ripple and the dc-link current ripple. 

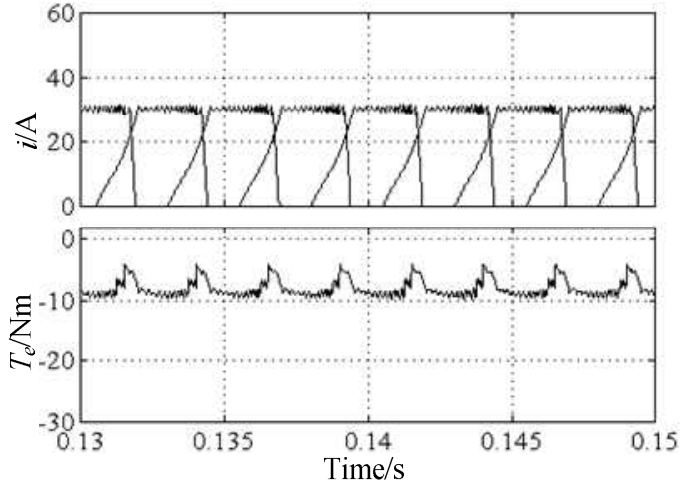

(a)
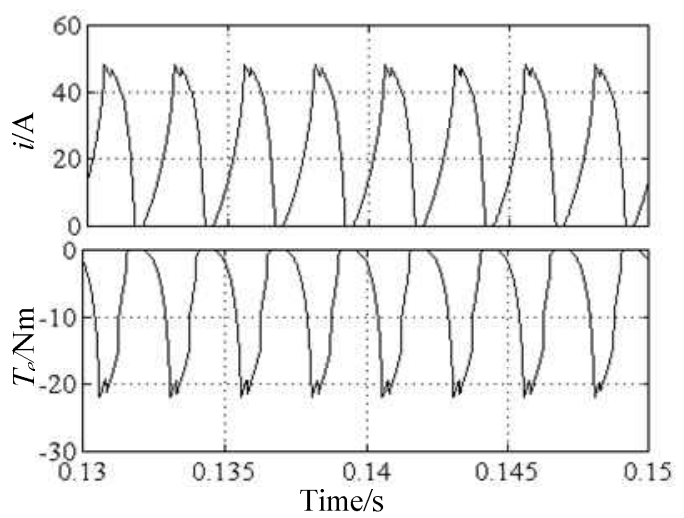

(b)

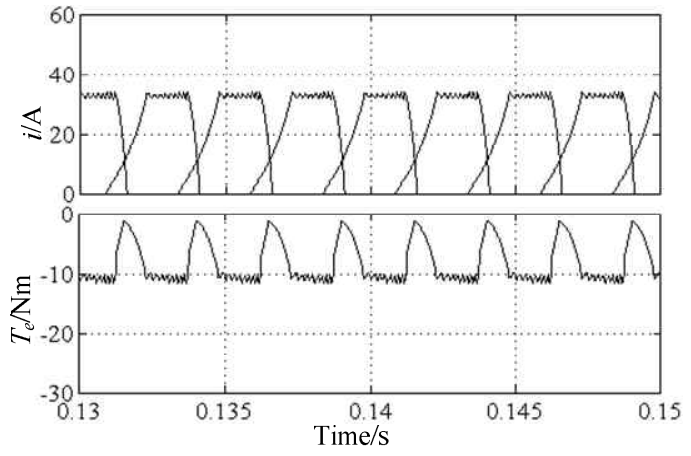

(c)

Fig. 15. Simulated optimization phase current and torque waveforms. (a) $f(\tau)$ optimization. (b) $f(\eta)$ optimization.

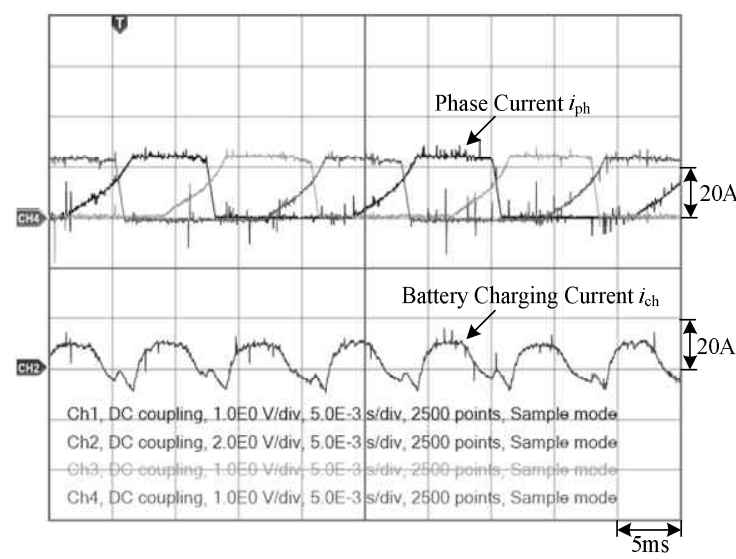

(a)

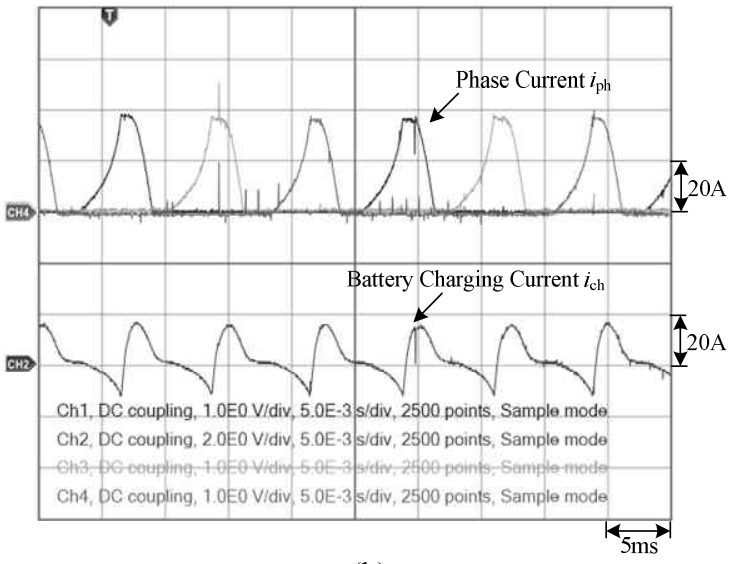

(b)

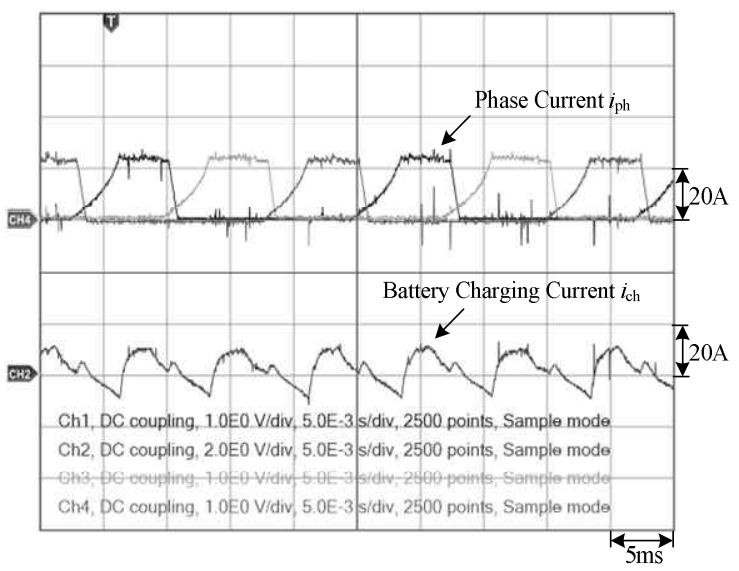

(c)

Fig.16. Experimental optimization phase current and charging current waveforms. (a) $f(\tau)$ optimization. (b) $f(\eta)$ optimization. (c) $f(\tau, \eta)$ optimization

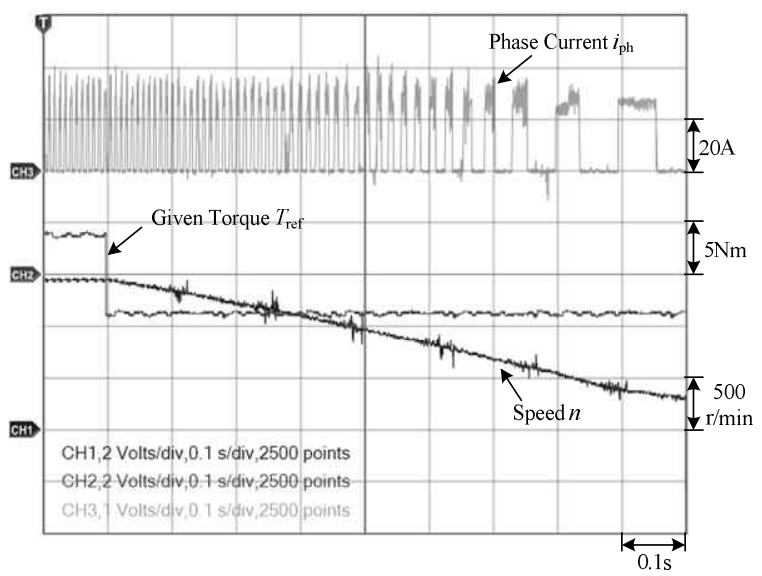

Fig.17. Experimental braking waveforms.

Fig. 17 shows the experimental braking waveforms. When the torque command is turned from motoring to braking, the conduction angle is moved to the inductance falling zone. The speed decreases quickly, and the braking energy is converted into electrical energy stored in the battery. This increases the driving mileage of EVs per charge. 


\section{CONCLUSIONS}

In order to improve the dynamic performance and steady-state accuracy of the braking torque when EVs run in the braking state, the braking torque closed-loop control of the SRM is proposed. A hysteresis current regulator with a soft chopping mode is employed to reduce the switching frequency and switching loss. The estimated torque only lags behind the actual torque by one electrical period with the designed torque estimator which can give feedback to the torque regulator fast. The feed-forward segment increases the dynamic response speed and the saturation compensation segment eliminates the static error in the proposed composite torque regulator. The turn-on and turn-off angles of the SRM are optimized by a GA, which improves the braking energy feedback efficiency and reduces both the braking torque ripple and the dc-link current ripple. The simulation and experimental results verify the effectiveness of the proposed control strategies.

\section{ACKNOWLEDGMENT}

The research in this paper is supported by "the Fundamental Research Funds for the Central Universities (China University of Mining and Technology) 2014ZDPY33 and a Project Funded by the Priority Academic Program Development of Jiangsu Higher Education Institutions. The authors show gratefully acknowledgment.

\section{REFERENCES}

[1] H. Chen and J. J. Gu, "Implementation of three-phase switched reluctance machine system for motors and generator," IEEE/ASME Trans. Mechatron., Vol. 15, No. 3, pp. 421-432,Jun. 2010.

[2] R. Krishnan, "Switched reluctance motor drives," Boca Raton: CRC Press, 2001

[3] H. Zeng, Z. Chen, and H. Chen, "Smooth torque speed characteristic of switched reluctance motors," Journal of Power Electronics, Vol. 14, No. 2, pp. 341-350, Mar. 2014.

[4] K. Ohyama, M. N. F. Nashed, K. Aso, H. Fujii, and H. Uehara, "Design using finite element analysis of a switched reluctance motor for electric vehicle," Journal of Power Electronics, Vol. 6, No. 2, pp. 163-171, Apr. 2006.

[5] N. Schofield, S. A. Long, D. Howe, and M. McClelland, "Design of a switched reluctance machine for extended speed operation," IEEE Trans. Ind. Appl., Vol.45, No. 1, pp.116-122, Jan. 2009.

[6] B. Fahimi, A. Emadi, and B. S. J. Raymond, "A switched reluctance machine-based starter/alternator for more electric cars," IEEE Trans. Energy Convers., Vol. 19, No. 1, pp.116-124, Mar. 2004.

[7] S. J. Song, W. G. Liu, and U. Schaefer, "Optimal control of a high speed switched reluctance starter/generator for the more/all electric aircraft," Transactions of China Electrotechnical Society, Vol. 25, No. 4, pp. 44-52, Apr. 2010.

[8] R. Cardenas, R. Pena, and M. Perez, "Power smoothing using a flywheel driven by a switched reluctance machine," IEEE Trans. Ind. Electron., Vol. 53, No. 4, pp. 1086-1093, Aug. 2006

[9] Y. J. Bao, K. W. E. Cheng, N. C. Cheung, and S. L. Ho, "Experimental examination on a new switched reluctance wind power generator system for electric vehicles," IET Power Electronics, Vol. 5, No. 8, pp.1262-1269, Jul. 2012.

[10] Y. C. Chang and C. M. Liao, "Establishment of a switched-reluctance generator-based common dc micro grid system," IEEE Trans. Power Electron., Vol. 26, No. 9, pp. 2512-2527, Sep. 2011.

[11] V. Valdivia, R. Todd, F. J. Bryan, A. Barrado, A. Lázaro, and A. J. Forsyth, "Behavioral modeling of a switched reluctance generator for aircraft power systems," IEEE Trans. Ind. Electron., Vol. 61, No. 6, pp. 2690-2699, Jun. 2014.

[12] X. S. Zan and H. Chen, "Rotating speed closed loop study of switched reluctance motor based on auto disturbance rejection control," Transactions of China Electrotechnical Society, Vol. 27, No. 7, pp. 17-25, Jul. 2012.

[13] X. D. Xue, K. W. E. Cheng, J. K. Lin, Z. Zhang, K. F. Luk, T. W. Ng, and N. C. Cheung, "Optimal control method of motoring operation for srm drives in electric vehicles," IEEE Trans. Veh. Technol., Vol. 59, No. 3, pp. 1191-1204, Mar. 2010.

[14] Y. C. Chang and C.M. Liao, "On the design of power circuit and control scheme for switched reluctance generator," IEEE Trans. Power Electron., Vol. 23, No. 1, pp. 445-454, Jan. 2008.

[15] Y. Sozer and D. A. Torrey, "closed loop control of excitation parameters for high speed switched reluctance generators," IEEE Trans. Power Electron., Vol. 19, No. 2, pp. 355-362, Mar. 2004.

[16] C. Sikder, I. Husain, and Y. Sozer, "Switched reluctance generator control for optimal power generation with current regulation," IEEE Trans. Ind. Appl., Vol. 50, No. 1, pp. 307-316, Jan. 2014.

[17] M. Dowlatshahi, S. M. Saghaiannejad, J. W. Ahn, and M. Moallem, "Copper loss and torque ripple minimization in switched reluctance motors considering nonlinear and magnetic saturation effects," Journal of Power Electronics, Vol. 14, No. 2, pp. 351-361, Mar. 2014.

[18] H. Hannoun, M. Hilairet, and C. Marchand, "Design of an SRM speed control strategy for a wide range of operating speeds," IEEE Trans. Ind. Electron., Vol. 57, No. 9, pp. 2911-2921, Sep. 2010.

[19] K. M. Rahman and S. E. Schulz, "High-performance fully digital switched reluctance motor controller for vehicle propulsion," IEEE Trans. Ind. Appl., Vol. 38, No. 4, pp. 1062-1071, Jul. 2002.

[20] C. Mademlis and I. Kioskeridis, "Gain-scheduling regulator for high-performance position control of switched reluctance motor drives," IEEE Trans. Ind. Electron., Vol. 57, No. 9, pp. 2922-2931,Sep. 2010.

[21] Z. Lin, D. Reay, B. Williams, and X. He, "High-performance current control for switched reluctance motors based on on-line estimated parameters," IET Electric Power Applications, Vol. 4, No. 1, pp. 67-74, May 2010.

[22] S. Venkatraman and G. G. Yen, "A generic framework for constrained optimization using genetic algorithms," IEEE Trans. Evol. Comput., Vol. 9, No. 4, pp.424-435, Aug. 2005. 


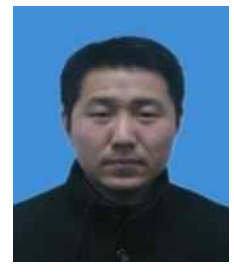

He Cheng received his B.S. degree from the School of Information and Electrical Engineering, China University of Mining and Technology, Xuzhou, China, in 2010. $\mathrm{He}$ is presently working toward his Ph.D. degree in the School of Information and Electrical Engineering, China University of Mining and Technology.

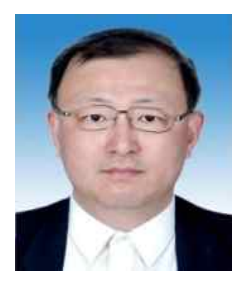

Hao Chen (SM'08) received his B.S. and Ph.D. degrees from the Department of Automatic Control, Nanjing University of Aeronautics and Astronautics, Nanjing, China, in 1991 and 1996, respectively. In 1998, he became an Associate Professor in the School of Information and Electrical Engineering, China University of Mining and Technology, Xuzhou, China, where he has been a Professor since 2001. From 2002 to 2003, he was a Visiting Professor at Kyungsung University, Busan, Korea. Since 2008, he has also been an Adjunct Professor at the University of Western Australia, Perth, Australia. He is the author of one book and more than 170 papers. He has obtained 17 Chinese Invention Patents and 6 Chinese Utility Model Patents. His current research interests include motor control, linear launchers, electric vehicles, electric traction, servo drives, and wind power generator control. Professor Chen won the Prize of Science and Technology of Chinese Youth and the Prize of the Fok Ying Tong Education Foundation for Youth Teachers, both in 2004. He was awarded second prize by the Science and Technology Advanced of Province and Ministry 6 times, and he was awarded third prize 13 times. He became a Chinese New Century Hundred, Thousand, and Ten Thousand Talents member for Engineering National Talent, in 2007. He has received a Government Especial Allowance from the People's Republic, China State Department, since 2006.

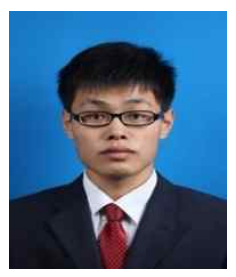

Zhou Yang received his B.S. degree from the College of Information and Control Engineering, China University of Petroleum, Qingdao, China, in 2012. He is presently working toward his M.S. degree in the School of Information and Electrical Engineering, China University of Mining and Technology, Xuzhou, China.

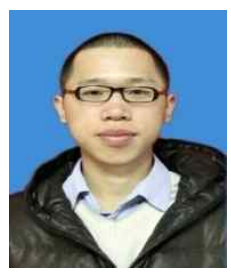

Weilong Huang received his B.S. degree from the College of Information and Control Engineering, Jilin University of Chemical Technology, Jilin, China, in 2013. He is presently working toward his M.S. degree in the School of Information and Electrical Engineering, China University of Mining and Technology, Xuzhou, China. 